\title{
A city park as a potential epidemic site of scrub typhus: a case-control study of an outbreak in Guangzhou, China
}

\author{
Yuehong Wei ${ }^{1}$, Lei Luo ${ }^{1}$, Qinlong Jing ${ }^{1}$, Xiaoning Li ${ }^{2}$, Yong Huang ${ }^{1}$, Xincai Xiao ${ }^{1}$, Lan Liu' ${ }^{1}$, Xinwei Wu ${ }^{1}$ \\ and Zhicong Yang ${ }^{1 *}$
}

\begin{abstract}
Background: Scrub typhus is an important public health problem in China, especially in Guangzhou city. Typical outbreaks of scrub typhus have been previously reported in rural areas, affecting mainly farmers. We describe an atypical outbreak of the disease with case fatalities, from a park in Haizhu District, Guangzhou, that could turn out to be a potential scrub typhus epidemic site.

Methods: From May 2012 to June 2012, a case-control study was conducted to identify source and risk factors of this outbreak. Reported cases of scrub typhus in Xiaogang Park were confirmed by Weil-Felix test or a nested polymerase chain reaction (NPCR). Controls were matched with their neighbors by gender and age. Multivariate conditional logistic regression was used to identify risk factors and protective factors.

Results: A total of 29 cases were confirmed by Weil-Felix test, including 4 deaths by both Weil-Felix test and NPCR. All patients presented with fever (100\%), while 28 (96.6\%) cases had eschars, 10 (34.5\%) headache, 10 (34.5\%) chills, 6 (20.7\%) lymphadenopathy, 5 (17.2\%) rash, 2 (6.9\%) vomiting and 1 (3.5\%) presented with conjunctival congestion. The proportion of cases with activity history in Xiaogang Park was much higher than the control group (72.4\% vs $24.1 \%, P<0.001$ ), and morning exercise in park or field was also as a risk factor for scrub typhus (adjusted $\mathrm{OR}=3.0,95 \% \mathrm{Cl}: 1.1-8.2$ ). Four factors were significantly associated with the risk of developing scrub typhus: sitting on the lawn (adjusted $\mathrm{OR}=8.0,95 \% \mathrm{Cl}: 1.4-44.5$ ), close contact with rats (adjusted $\mathrm{OR}=3.3,95 \% \mathrm{Cl}: 1.2$-9.6), sitting near the rat holes $(\mathrm{OR}=6.8,95 \% \mathrm{Cl}: 1.2-38.1)$ and wearing long-sleeved clothing when outside (adjusted $\mathrm{OR}=0.3,95 \% \mathrm{Cl}: 0.1-0.7)$.

Conclusions: We confirmed an atypical outbreak of scrub typhus in a park in Guangzhou city, which has the potential to develop into an important epidemic site. This public health risk should not be neglected and requires more attention from authorities.
\end{abstract}

Keywords: City, Park, Scrub typhus, Epidemiology

\section{Background}

Scrub typhus (Tsutsugamushi disease) is a febrile illness caused by the rickettsial bacterium, Orientia tsutsugamushi. It is transmitted by the bites of infected chiggers of the Trombiculidae family, especially those of the genus Leptotrombidium [1]. Clinical presentation in patients varies from an asymptomatic to a life-threatening disease,

\footnotetext{
* Correspondence: yangzc@gzcdc.org.cn

'Guangzhou Center for Disease Control and Prevention, Guangzhou,

Guangdong Province, China

Full list of author information is available at the end of the article
}

including acute respiratory distress syndrome and acute liver failure [2]. To date, no effective and reliable human vaccine against scrub typhus is available [3].

The epidemic occurs mainly in Asia and the Pacific [4-7], wherein Japan, Korea and China are renowned as 'the triangle of scrub typhus' [8-11]. It is estimated that over half $(55 \%)$ of the world's population live in scrub typhus endemic areas, and that about one million cases occur annually [12].

As a natural epidemic focus, the habitat conditions of scrub typhus include weeds along rivers, shrub, grassland 
and abandoned farmlands. People engaged in agriculture and forestry are at high risk for scrub typhus. In recent decades, with the economic development [2], population movement, urbanization [13], climatic changes and the overutilization of natural resources, the epidemic focus is expanding continuously [14]. The incident population have spread from occupational population to general population such as the elderly, children, pregnant women and tourists [2,15-17].

In 1948, the first Chinese case of scrub typhus case was reported in Guangzhou, and was later spread to other provinces, including Shandong, Anhui and Beijing $[1,5,14]$. Due to its severity, scrub typhus is a reportable disease in China. A total of 27,391 confirmed cases of scrub typhus were reported in China during 2006-2012, with southeastern and southwestern China reporting higher numbers [8]. From 2006 to 2012 Guangzhou reported a total of 3997 confirmed cases with an obvious increase of reported cases in 2012.

In China, outbreaks of scrub typhus are typically reported in rural areas, and it is primarily farmers are who are infected. To the best of our knowledge, there is no previous report describing citizens acquiring scrub typhus from an urban park. From May 2012, a large number of patients with fever, headache, lymphadenopathy and rash were discovered from our surveillance system, 4 fatal cases were diagnosed as scrub typhus. As scrub typhus seldom causes death in Guangzhou, it attracted our attention. Here, we confirm an atypical outbreak of scrub typhus with fatal cases through use of laboratory diagnosis and epidemiological investigation. This outbreak occurred in a park in Haizhu District, Guangzhou, China, which has potential to become a scrub typhus epidemic focus due to its usage by the public.

\section{Methods}

Study area

Guangzhou (Figure 1) is the capital of Guangdong province of China, It is located between longitudes $112^{\circ} 57^{\prime} \mathrm{E}$ and $114^{\circ} 3^{\prime} \mathrm{E}$, latitudes $22^{\circ} 26^{\prime} \mathrm{N}$ and $23^{\circ} 56^{\prime} \mathrm{N}$. The city population in 2010 was 12.70 million [18]. It is influenced by a subtropical monsoon climate, yielding hot rainy summers and mild winters. The average January temperature is about $0^{\circ} \mathrm{C}$, while the corresponding July temperature hovers around $25^{\circ} \mathrm{C}$. The annual rainfall is between $1500 \mathrm{~mm}$ to $2000 \mathrm{~mm}$ and occurs mainly in summer. There is subtle difference in humidity between summer and winter due to a considerable amount of precipitation in winter. Subtropical evergreen broad-leaved forest is the main vegetation of Guangzhou, and the green coverage rate is $24.57 \%$.

Xiaogang Park (Figure 2) with an area of $167,000 \mathrm{~m}^{2}$, is located in the southwest of Haizhu District, Guangzhou and has a wide grass coverage. In the park, the Greenery pottery workshop, Picnic place and Shi Ma Gang are the places with the most people-related activity. Between 19 to 26 May 2012, 4 fatal cases with fever, headache, eschar, lymphadenopathy and rash were discovered in Haizhu District, Guangzhou. Case survey showed that they all had history of activity in Xiaogang Park, so we conducted research in that area by a questionnaire in order to identify the association between the outbreak and the park.

\section{Study design}

A retrospective case-control study was designed for identifying the source of this outbreak. A case was defined as any scrub typhus patient reported between 1 May and 20 June in Haizhu district. For every case, four controls were sought in the neighborhood. These controls were of the same gender, within 2 years' age difference, and lived in the same building or within 50 meters away from the respective case. Trained investigators visited and interviewed both the cases and controls with the same structured questionnaire. The questionnaire consisted of five parts: social and demographic characteristics (age, gender, occupation and residence), clinical features (onset date, history of disease, complication, fever, rash, eschar, chills, headache, conjunctival congestion and vomiting), history of outdoor activities within one month from onset (travelling, morning exercise and activity history in Xiaogang Park), potential risk factors (sitting on the lawn, fishing, close contact with cats, close contact with rats, sitting next to rat holes, keeping dogs and cats) and potential protective factors of scrub typhus (wearing long-sleeved clothing when outside and using insect repellent).

\section{Diagnosis and laboratory investigation of cases}

The diagnostic criteria for scrub typhus were based on a guidebook published by the Chinese Center for Disease Control and Prevention (China CDC) [19]. Patients with two of the following were defined as clinically diagnosed cases: (i) field exposure history 1-3 weeks prior to onset of symptoms, (ii) sudden high fever accompanied by characteristic eschar or ulcer, (iii) enlarged lymph nodes, skin rash, splenomegaly, or hepatomegaly. The confirmed scrub typhus case was defined as: agglutination titer $>1: 160$ in the Weil-Felix test using the OX-K strain of Proteus mirabilis, or a positive 56-kD nested polymerase chain reaction (NPCR) test. For the NPCR test [20], DNA was extracted from blood clots using a blood DNA extraction kit (Invitrogen, China). The Orientia tsutsugamushi $56-\mathrm{kDa}$ protein gene was amplified by nested PCR. The outside primer pair comprised TACAT TAGCTGCGGGTATGACA and CCAGCATAATTCTT CAACCAAG. The nested primer pair comprised GAGC AGAGCTAGGTGTTATGTA and TAGGCATTATAGT AGGCTGAGG. PCR products were 306 to $339 \mathrm{bp}$ for the outside primer pair and 150 to $168 \mathrm{bp}$ for the nested 


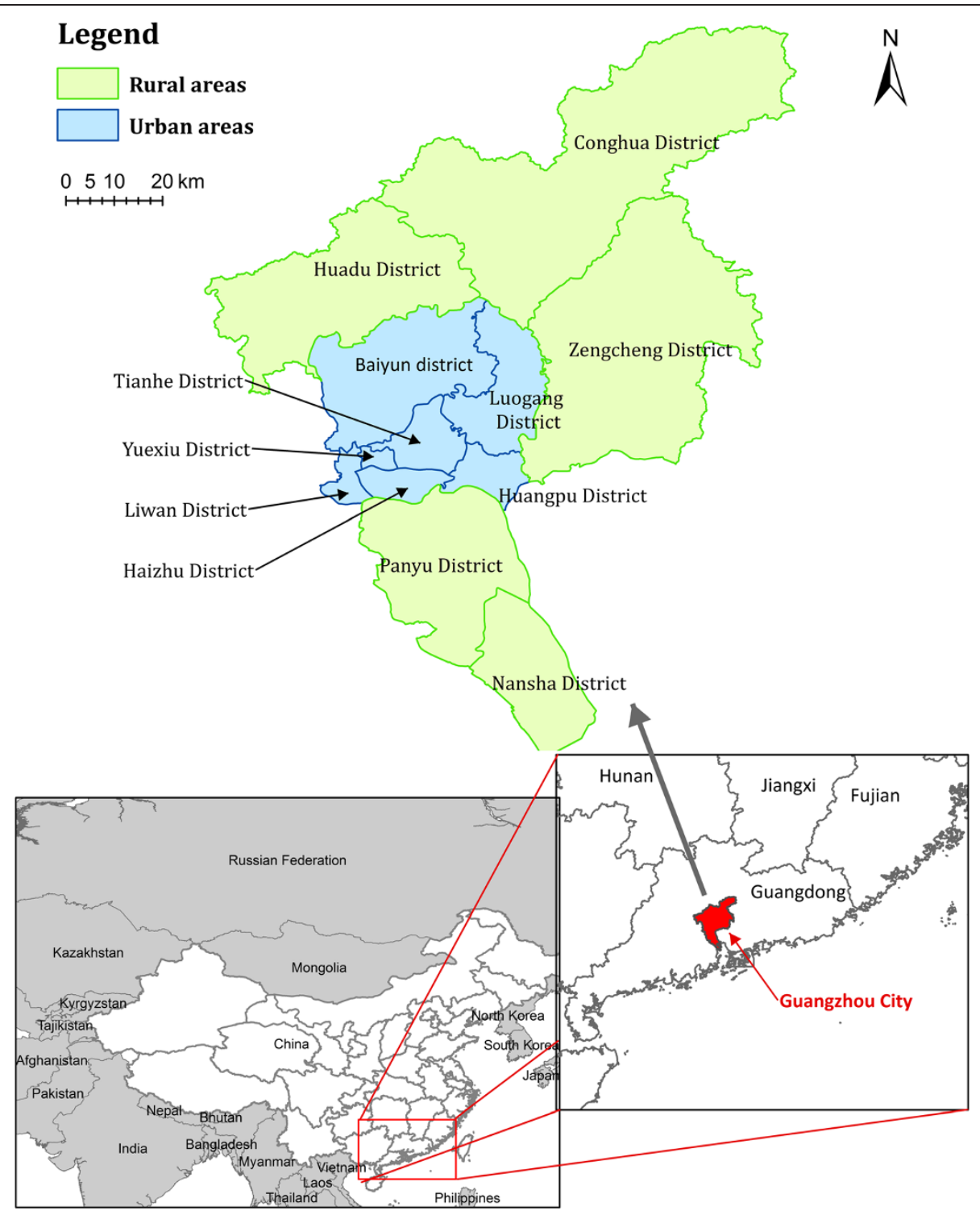

Figure 1 Geographic location of Guangzhou City, Guangdong Province, China.

primer pair. PCR conditions were the same for both primer pairs, with initial denaturation for $5 \mathrm{~min}$ at $94^{\circ} \mathrm{C}$, followed by 35 cycles of $1 \mathrm{~min}$ at $94^{\circ} \mathrm{C}, 1 \mathrm{~min}$ at $50^{\circ} \mathrm{C}$, and $1 \mathrm{~min}$ at $72^{\circ} \mathrm{C}$, and a final extension of $5 \mathrm{~min}$ at $72^{\circ} \mathrm{C}$. PCR products were separated by electrophoresis, stained with ethidium bromide, and recorded by using the BioRad gel imaging system.

\section{Informed consent and ethical issues}

We obtained verbal informed consent from all study subjects. This study and the use of oral consent procedures were reviewed and approved by Guangzhou Center for Disease Control and Prevention Ethics Committee and Guangzhou Health Bureau.

\section{Statistic analysis}

Data was entered using Epidata 3.1(Epidata Association, Odense, Denmark) and SPSS 20.0 (IBM SPSS, Chicago, Illinois) was used for statistic analysis. Quantitative data were described by means and standard deviation, while socioeconomic status of cases and controls was compared by conditional logistic regression. Multivariate conditional logistic regression was used to evaluate the potential risk factors and protective factors. The crude odds ratios (ORs) and adjusted ORs (adjusted for age, and gender) and their 95\% confidence intervals $(\mathrm{CI})$ were reported.

\section{Results}

We identified a total of 29 scrub typhus cases. The first case was reported on 1 May 2012 and the last case was 


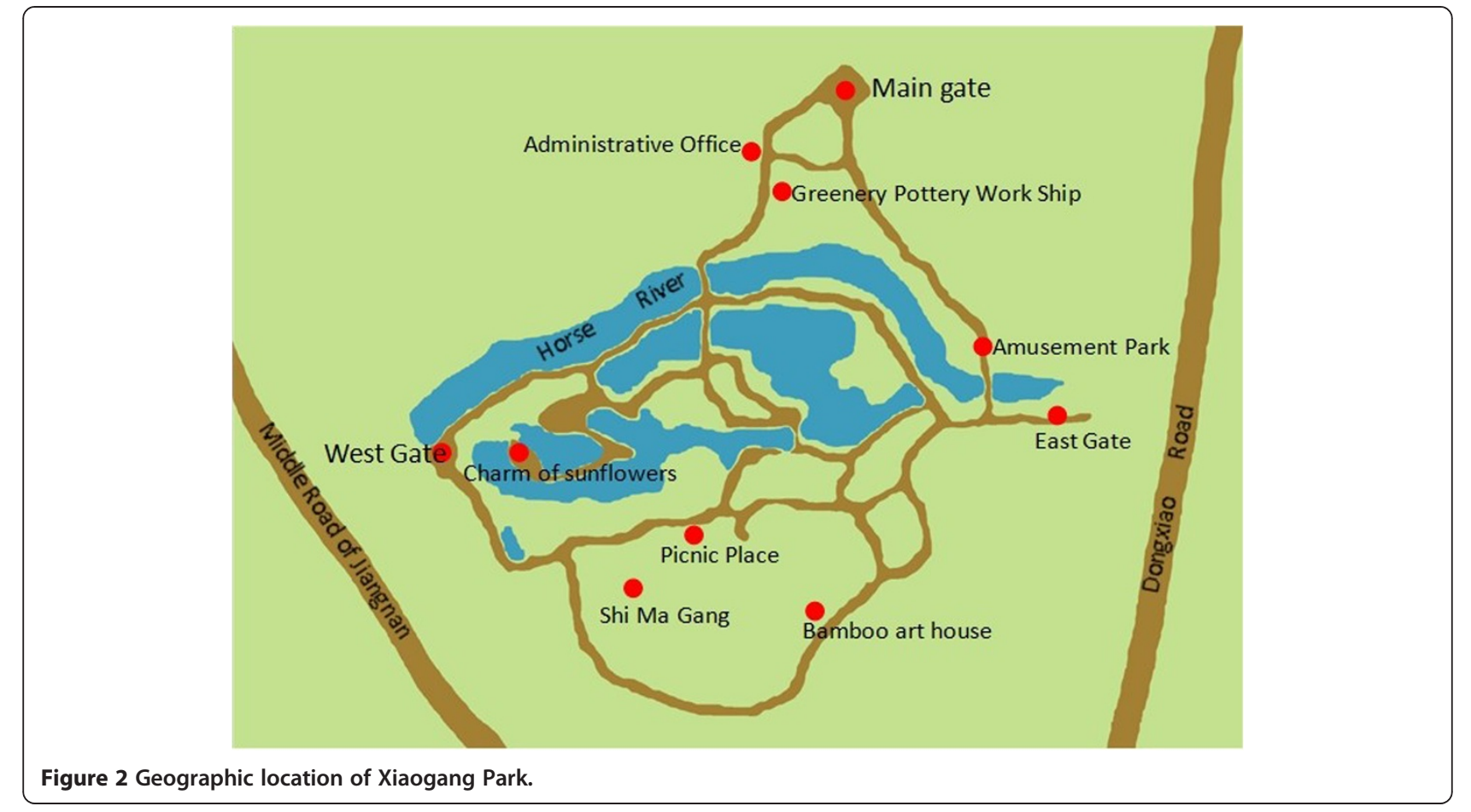

reported on 17 June 2012. Fourteen (48.3\%) patients were men. The age of patients ranged from 24 to 86 years, with a median age of 58 years. There were four fatal cases that included one male and three females, all over 70 years of age, and the mortality rate was $13.8 \%(4 / 29)$.

\section{Clinical feature and Laboratory results}

Eschars were found in 28 (96.6\%) patients. With regard to other symptoms, all patients had fever (100\%), while 10 with headache, 10 with chills. Lymphadenopathy, rash, vomiting and conjunctival congestion were seen in 6, 5, 2 and 1 instances respectively. All 29 cases were confirmed by Weil-Felix test, of which the genotype Karp type was identified by NPCR in the 4 fatal cases (Table 1).

\section{Case-control study}

\section{Demographic characteristic}

Table 2 shows the demographic profiles for the 29 cases and 116 controls. The age group 40-79 years had the predominant number of cases $23 / 29$. Two-thirds of cases had been educated up to junior middle school (Grade 7-9, about 12-15years old). There was only one farmer among the cases. For occupation, 3.4\% (1/29) of the cases and $2.6 \%(3 / 116)$ of the controls were farmers. There was no significant difference in gender, age, education and occupation between cases and controls ( $p>0.05)$.

\section{History of outdoor activities and risk behavior}

Table 3 shows the crude ORs and adjusted ORs for outdoor activities history and Xiaogang Park activity history. People who took their morning exercise in the park or field within the study period had significantly higher risk (adjusted OR $=3.0,95 \%$ CI: 1.1 - 8.2), People who had activities in Xiaogang Park had a higher risk than those who did not (adjusted OR = 9.1, 95\% CI: 3.3 - 25.5). Activities in the Greenery pottery workshop had significantly higher risk of disease (adjusted OR $=4.6,95 \% \mathrm{CI}$ : 1.7- 12.5). There was no significant difference between cases and controls with regard to activity in the Picnic place or Shi Ma Gang.

Table 1 The demographic and clinical features of the 4 death cases

\begin{tabular}{|c|c|c|c|c|c|c|c|c|}
\hline Cases & Age & Gender & Onset date & History of disease & Clinical features & Complication & Genotype & Death date \\
\hline 1 & 71 & Female & May 16th & Hypertension; hemorrhoids & Fever; headache; rash & severe pneumonia & Karp & May 28th \\
\hline 2 & 73 & Female & May 14th & Hypertension; CHD; pneumonia & Fever; diarrhea; bloody stool & $\begin{array}{l}\text { multiple organ } \\
\text { function lesion }\end{array}$ & Karp & May 24th \\
\hline 3 & 77 & Female & May 12th & Hypertension; hemorrhoids & Fever; cough; rash; vomiting & pneumonia & Karp & May 22th \\
\hline 4 & 57 & Male & May 15th & 10 years of chest distress & Fever; rash; chilled; convulsion & $\begin{array}{l}\text { multiple organ } \\
\text { function lesion }\end{array}$ & Karp & May 22th \\
\hline
\end{tabular}


Table 2 Demographic characteristics of the cases and controls in this outbreak

\begin{tabular}{|c|c|c|c|c|c|}
\hline \multirow[t]{2}{*}{ Characteristic } & \multicolumn{2}{|c|}{ Case } & \multicolumn{2}{|c|}{ Control } & \multirow[t]{2}{*}{$\mathbf{P}$} \\
\hline & No. & $\%$ & No. & $\%$ & \\
\hline Gender & & & & & - \\
\hline Male & 14 & 46.9 & 56 & 46.9 & \\
\hline Female & 15 & 53.1 & 60 & 53.1 & \\
\hline Age, year & & & & & - \\
\hline 20-39 & 4 & 13.8 & 12 & 10.3 & \\
\hline $40-59$ & 13 & 44.8 & 50 & 43.1 & \\
\hline $60-79$ & 10 & 34.5 & 47 & 40.5 & \\
\hline$\geq 80$ & 2 & 6.9 & 7 & 6 & \\
\hline Education & & & & & 0.371 \\
\hline Junior middle school & 20 & 69 & 74 & 63.8 & \\
\hline High school & 3 & 10.3 & 25 & 21.6 & \\
\hline Junior college & 3 & 10.3 & 12 & 10.3 & \\
\hline Bachelor or above & 3 & 10.3 & 5 & 4.3 & \\
\hline Occupation & & & & & 0.800 \\
\hline Farming related & 1 & 3.4 & 3 & 2.6 & \\
\hline Non-farming & 28 & 96.6 & 113 & 97.4 & \\
\hline
\end{tabular}

For risk behaviors in the adjusted model, sitting on the lawn (adjusted OR $=8.0,95 \%$ CI:1.4 - 44.5), close contact with rats (adjusted OR $=3.3,95 \%$ CI: 1.2 - 9.6) and sitting near the rat holes $(\mathrm{OR}=6.8,95 \% \mathrm{CI}: 1.2-38.1)$ significantly increased the risk for scrub typhus (Table 3 ). For protective behaviors, wearing long-sleeved clothing while being outdoors was negatively associated with the risk of disease (adjusted OR $=0.3,95 \%$ CI: 0.1 - 0.7), insect repellent use did not show a significant association.

\section{Response to the epidemic}

After 25 May, 2012, the Xiaogang Park was renovated to bring more sunlight and reduce humidity, renovation included lawn mowing and filling of potholes. Pyridaben was used in areas that could not be weeded; bromadiolone was used in the Greenery pottery workshop, picnic place and Shi Ma Gang to control rats. Since the control measures, no new scrub typhus case has been reported in association with the park.

\section{Discussion}

This was an atypical outbreak of scrub typhus associated with a park in Guangzhou. The outbreak, affected 29 people and caused 4 deaths, it was considered unusual as relatively few outbreaks had been previously reported

Table 3 Activity history, risk factors and protect factor of the scrub typhus in this outbreak*

\begin{tabular}{|c|c|c|c|c|}
\hline Exposure within one month & Case $(n=29)$ No. $(\%)$ & Controlt $(n=116)$ No.(\%) & Crude OR(95\% CI) & Adjusted OR(95\% Cl)‡ \\
\hline \multicolumn{5}{|l|}{ Outdoor activity history } \\
\hline Travelling & $24(82.8)$ & 102(87.9) & $0.7(0.2,2.0)$ & $0.5(0.2,1.9)$ \\
\hline Morning exercise in park or field & $22(75.9)$ & $64(55.2)$ & $2.6(1.0,6.4)$ & $3.0(1.103,8.2)$ \\
\hline Activity history in Xiaogang Park & $21(72.4)$ & $28(24.1)$ & $8.3(3.8,20.7)$ & $9.1(3.267,25.5)$ \\
\hline Activity history in other parks & $9(31.0)$ & $28(24.1)$ & $1.4(0.6,3.5)$ & $1.5(0.587,3.8)$ \\
\hline \multicolumn{5}{|l|}{ Activity places in Xiaogang Park } \\
\hline Picnic place & $9(31.0)$ & $34(29.3)$ & $1.1(0.4,2.6)$ & $1.2(0.5,3.1)$ \\
\hline Shi Ma Gang & $5(17.2)$ & $27(23.3)$ & $0.7(0.2,2.0)$ & $0.7(0.2,2.3)$ \\
\hline Greenery pottery work ship & 16(55.2) & $33(28.4)$ & $3.1(1.3,7.1)$ & $4.6(1.7,12.5)$ \\
\hline \multicolumn{5}{|l|}{ Risk behaviors } \\
\hline Sitting on lawn & $5(18.5)$ & $3(2.8)$ & $8.0(1.8,35.8)$ & $8.0(1.4,44.5)$ \\
\hline Fishing & $6(20.7)$ & 15(12.9) & $1.8(0.6,5.0)$ & $2.2(0.6,7.9)$ \\
\hline Close contact with cats & $3(10.3)$ & $5(4.3)$ & $2.6(0.6,11.4)$ & $2.4(0.4,13.6)$ \\
\hline Close contact with rats & $9(31.0)$ & 15(12.9) & $3.0(1.2,7.9)$ & $3.3(1.2,9.6)$ \\
\hline Sitting near rat holes & $7(24.1)$ & $9(7.8)$ & $3.8(1.3,11.2)$ & $6.8(1.2,38.1)$ \\
\hline Keep dogs & $4(13.8)$ & $14(12.1)$ & $0.9(0.3,2.8)$ & $0.9(0.3,3.0)$ \\
\hline Keep cats & $3(10.3)$ & $6(5.2)$ & $0.5(0.1,2.0)$ & $0.6(0.1,2.3)$ \\
\hline \multicolumn{5}{|l|}{ Protect behaviors } \\
\hline Wearing long-sleeved clothing & $8(27.6)$ & $62(53.4)$ & $0.3(0.1,0.8)$ & $0.3(0.1,0.7)$ \\
\hline Using insect repellent & $5(17.9)$ & $22(20.2)$ & $1.2(0.4,3.4)$ & $1.2(0.4,4.0)$ \\
\hline
\end{tabular}

*OR = odds ratio; $\mathrm{Cl}=$ confidence interval. 
in parks of metropolitan cities. The mortality rate was higher than that reported in South Korea [10], but was similar to that of Thailand [6]. Among the 29 cases, all had fever while eschar was found in $96.5 \%$ cases, which was more common than those reported from studies in Japan and Korea $[9,10]$.

The relationship between eschar and mortality was not concordant with a previous report that patients without eschar had $>$ six times risk of severe infection [9]. Though most of our patients had eschars, case fatalities were not negligible (13\%).

Karp genotype may have played a critical role in the fatal cases due to its higher virulence compared with other genotypes [11,21-23]. Importantly, all 4 fatal cases had severe chronic conditions, putting them at increased the risk of fatality [24]. The median age of cases was 58 , much higher than those reported from other areas $[8,9,25]$, it is to be anticipated that older, particularly elderly, scrub typhus patients will be more likely to develop complications, which may be one of the reasons contributing to the high mortality observed in this outbreak. In addition, since this outbreak occurred before the seasonal epidemic peak of Guangzhou, the time of diagnosis may have been delayed by insufficient awareness among clinicians.

The national surveillance in China showed that the proportion of scrub typhus cases among farmers increased from $58.51 \%$ in 2006 to $69.33 \%$ in 2012 , with farmer to non-farmer ratio of 1:1 in 2006 and 2:1 in 2012 [8]. Research has showed that farmers are the highest risk population for scrub typhus due to long term exposure in fields or orchards. However, barring one, none of our patients had been engaged in agricultural activities. Furthermore, there has recently been an increasing trend of non-farmer cases in Guangzhou; from 172 cases in 2006, to 689 cases in 2012. Further, the percentage of non-farmers among total number of cases was also much higher than the national average, ranging from $44.9 \%$ to $51.0 \%$ (data unpublished). This suggested that Guangzhou city is becoming a new epidemic focus of scrub typhus, and this infection among non-faming citizenry is gradually increasing. The traditional prevention and control programs often pay great attention to farmers without targeting other occupational groups. This outbreak is a reminder to us that the general public should not be ignored in prevention and control campaign of scrub typhus.

Scrub typhus in parks had been reported in other counties [26-28], but to the best of our knowledge, this is the first report in China. With the rapid development of our economy and urbanization, more people are breaking from their traditional farming or forestry activities. It seems to lower the risk of infection from vector-born infectious disease generally, however, the habitat conditions of scrub typhus includes not only farmlands, but also well-greened places such as grasslands in park. Moreover, park managers priorities may focus on protecting the grassland from damage rather than eliminate potential epidemic area, as a result, unfed chiggers are usually found on dead leaves or low lying vegetation awaiting a suitable host $[29,30]$. In recent years, rats in the park were found by vector surveillance, the capture rate of rats is as high as $10.4 \%$. The risk of contracting infection from chiggers has increased through ecotourism [31,32] and increasing leisure time in city park. When considering activities and infection risks in parks, we conclude that parks can become epidemic foci for scrub typhus infections.

Our study showed that activity history in the Greenery pottery workshop of Xiaogang Park was a risk factor for scrub typhus. Sitting on the lawn, close contacts with rats and sitting near the rat holes were risk factors and wearing long-sleeved clothing when outside was a protective factor. Use of insect repellent did not show significant protective effects. This suggests that workers exposed during outdoor activities are vulnerable to scrub typhus. Consequently, effective preventive measures should be taken and promoted.

All the cases in this outbreak were investigated at the early stage, thus recall bias was minimized in this casecontrol study. The disappearance of emerging cases after control measures was a further confirmation of the park as the epidemic focus. Nevertheless, our study is not without limitations. Firstly, our sample size is relatively small which weakens interpretation of the results of the case-control study. Secondly, the 29 non-fatal cases had recovered when we conducted the survey and they refused blood collection, so PCR confirmation was only conducted for the 4 fatal cases. Finally, we were unable to formally demonstrate that infective vectors were present in the park as Rickettsia ortientalis was not identified in chiggers which we collected at the last stage of the epidemic.

\section{Conclusions}

In China, outbreaks of scrub typhus are typically reported in rural areas, and farmers are primarily infected. We confirmed an atypical outbreak of Scrub Typhus in a park of Guangzhou, which might develop into an important epidemic site in the city. The risk of infection should not be neglected and we recommend more attention from public health authorities.

Competing interests

The authors declare that they have no competing interests.

\section{Authors' contributions}

$Y W, L L$ and $Z Y$ designed the study. $Y W, Y H, X L, X X, Q J$ and $X W$ performed the statistical analysis. $Y W, X L, L L, L L$ and $Z Y$ wrote the manuscript.

All authors read and approved the final manuscript.

Authors' information

Co-First authors: Yuehong Wei and Lei Luo. 


\section{Acknowledgements}

We thank all the participants in the study. We would also like to appreciate the efforts of medical and health institutions in Guangzhou City for disease reporting and data collection.

This study was supported by Medical Research Grant of Guangdong Province China (A2014586), Science and Technology Plan Grant of Guangzhou (2014-Y2-00080), Natural Science Foundation of China (81273139), Natural Science Foundation of Guangdong Province (S2013010013637), Science and Technology Plan Grant of Guangdong Province (2013B021800028) and The Project for Key Medicine Discipline Construction of Guangzhou Municipality (2013-2015-07).

\section{Author details}

'Guangzhou Center for Disease Control and Prevention, Guangzhou, Guangdong Province, China. ${ }^{2}$ School of Public Health, Guangdong Pharmaceutical University, Guangzhou, Guangdong Province, China.

Received: 17 July 2014 Accepted: 31 October 2014

Published online: 18 November 2014

\section{References}

1. Lyu Y, Tian L, Zhang L, Dou X, Wang X, Li W, Zhang X, Sun Y, Guan Z Li X, Wang Q: A case-control study of risk factors associated with scrub typhus infection in Beijing, China. PLoS One 2013, 8(5):e63668.

2. Lai $C H$, Huang $C K$, Weng $H C$, Dou $X$, Wang $X$, Li W, Zhang $X$, Sun $Y$, Guan $Z$, Li X, Wang Q: The difference in clinical characteristics between acute $Q$ fever and scrub typhus in southern Taiwan. Int J Infect Dis 2009, 13(3):387-393.

3. Valbuena G, Walker DH: Approaches to vaccines against Orientia tsutsugamushi. Front Cell Infect Microbiol 2012, 2:170.

4. Su TH, Liu CJ, Chen DS, Kao JH: Milder clinical manifestation of scrub typhus in Kinmen, Taiwan. J Formos Med Assoc 2013, 112(4):201-207.

5. Liu YX, Feng D, Suo JJ, Xing YB, Liu G, Liu LH, Xiao HJ, Jia N, Gao Y, Yang H, Zuo SQ, Zhang PH, Zhao ZT, Min JS, Feng PT, Ma SB, Liang S, Cao WC: Clinical characteristics of the autumn-winter type scrub typhus cases in South of Shandong Province, Northern China. BMC Infect Dis 2009, 9:82.

6. Rodkvamtook W, Gaywee J, Kanjanavanit S, Ruangareerate T, Richards AL, Sangjun N, Jeamwattanalert P, Sirisopana N: Scrub typhus outbreak, Northern Thailand, 2006-2007. Emerg Infect Dis 2013, 19(5):774-777.

7. Rosenberg R: Drug-resistant scrub typhus: Paradigm and paradox. Parasitol Today 1997, 13(4):131-132.

8. Zhang WY, Wang LY, Ding F, Hu WB, Soares MR, Sun HL, Liu YX, Liu QY, Huang LY, Clements AC, Li SL, Li CY: Scrub typhus in mainland China, 2006-2012: the need for targeted public health interventions. PLoS Negl Trop Dis 2013, 7(12):e2493.

9. Hashimoto S, Kawado M, Murakami Y, Izumida M, Ohta A, Tada Y, Shigematsu M, Yasui Y, Taniguchi K, Nagai M: Epidemics of vector-borne diseases observed in infectious disease surveillance in Japan, 2000-2005. J Epidemiol 2007, 17(Suppl):S48-S55.

10. Kweon SS, Choi JS, Lim HS, Kim JR, Kim KY, Ryu SY, Yoo HS, Park O: Rapid increase of scrub typhus, South Korea, 2001-2006. Emerg Infect Dis 2009, 15(7):1127-1129.

11. Zhang $M$, Zhao ZT, Yang $H L$, Zhang $A H$, Xu XQ, Meng XP, Zhang HY, Wang XJ, Li Z, Ding SJ, Yang L, Zhang LY: Molecular epidemiology of Orientia tsutsugamushi in chiggers and ticks from domestic rodents in Shandong, Northern China. Parasites Vectors 2013, 6(1):312.

12. Goswami D, Hing A, Das A, Lyngdoh M: Scrub typhus complicated by acute respiratory distress syndrome and acute liver failure: a case report from Northeast India. Int J Infect Dis 2013, 17(8):e644-e645.

13. Watt G, Kantipong P, Jongsakul K, Watcharapichat P, Phulsuksombati D, Strickman D: Doxycycline and rifampicin for mild scrub-typhus infections in Northern Thailand: a randomised trial. Lancet 2000 356(9235):1057-1061.

14. Zhang S, Song H, Liu Y, Li Q, Wang Y, Wu J, Wan J, Li G, Yu C, Li X, Yin W, Xu Z, Liu B, Zhang Q, Wan K, Li G, Fu X, Zhang J, He J, Hai R, Yu D, Walker DH, Xu J, Yu XJ: Scrub typhus in previously unrecognized areas of endemicity in China. J Clin Microbiol 2010, 48(4):1241-1244.

15. Kim YS, Lee HJ, Chang M, Son SK, Rhee YE, Shim SK: Scrub typhus during pregnancy and its treatment: a case series and review of the literature. Am J Trop Med Hyg 2006, 75(5):955-959.
16. Kumar M, Krishnamurthy S, Delhikumar CG, Narayanan P, Biswal N, Srinivasan S: Scrub typhus in children at a tertiary hospital in Southern India: clinical profile and complications. J Infect Public Health 2012, 5(1):82-88.

17. Lee CS, Hwang JH, Lee HB, Kwon KS: Risk factors leading to fatal outcome in scrub typhus patients. Am J Trop Med Hyg 2009, 81(3):484-488.

18. Guo Z, Jia J: Guangzhou Statistical Yearbook. Beijing: China Statistics Press; 2012

19. Chinese Center for Disease Control and Prevention. [http://www.chinacdc. cn/tzgg/200901/t20090105_40316.htm] 2009.

20. Kim JH, Roh JY, Kwon DH, Kim YH, Yoon KA, Yoo S, Noh SJ, Park J, Shin EH, Park MY, Lee SH: Estimation of the genome sizes of the chigger mites Leptotrombidium pallidum and Leptotrombidium scutellare based on quantitative PCR and k-mer analysis. Parasites Vectors 2014, 7(1):279.

21. CHEN XR: Scrub Typhus and Orientia Tsutsugamushi. Beijing: Military Medical Science Press; 2001.

22. Yu ES: Studies on Scrub Typhus in China. Hongkong: Asia Medicine Press; 2000.

23. Chen Z, Liu Q, Liu JQ, Xu BL, Lv S, Xia S, Zhou XN: Tick-borne pathogens and associated co-infections in ticks collected from domestic animals in Central China. Parasites Vectors 2014, 7(1):237.

24. Kumar V, Kumar V, Yadav AK, lyengar S, Bhalla A, Sharma N, Aggarwal R, Jain $S$, Jha V: Scrub typhus is an under-recognized cause of acute febrile illness with acute kidney injury in India. PLoS Negl Trop Dis 2014, 8(1):e2605

25. Varghese GM, Abraham OC, Mathai D, Thomas K, Aaron R, Kavitha ML, Mathai E: Scrub typhus among hospitalised patients with febrile illness in South India: magnitude and clinical predictors. J Infect 2006, 52(1):56-60.

26. Saxena VK: Chigger mite infestation of small mammals in a feral biotope of a public park area of south Delhi. J Commun Dis 1989, 21(4):360-364.

27. Ralph A, Raines $M$, Whelan $P$, Currie BJ: Scrub typhus in the Northern Territory: exceeding the boundaries of Litchfield National Park. Commun Dis Intell Q Rep 2004, 28(2):267-269.

28. Takahashi M, Murata M, Machida K, Hori E, Kawamura AJ, Tanaka H: Aggregated distribution of infective spots composed of Leptotrombidium pallidum, highly prevalent with Rickettsia tsutsugamushi, demonstrated by sentinel voles, Microtus montebelli, on the ground. Jpn J Exp Med 1990, 60(6):325-335.

29. Chuluun B, Mariana A, Ho T, Mohd KB: A preliminary survey of ectoparasites of small mammals in Kuala Selangor Nature Park. Trop Biomed 2005, 22(2):243-247.

30. Hii SF, Abdad MY, Kopp SR, Stenos J, Rees RL, Traub RJ: Seroprevalence and risk factors for Rickettsia felis exposure in dogs from Southeast Queensland and the Northern Territory. Aust Parasites Vectors 2013, 6(1):159.

31. Jeong YJ, Kim S, Wook YD, Lee JW, Kim KI, Lee SH: Scrub typhus: clinical, pathologic, and imaging findings. Radiographics 2007, 27(1):161-172.

32. Hii SF, Kopp SR, Thompson MF, O'Leary CA, Rees RL, Traub RJ: Molecular evidence of Rickettsia felis infection in dogs from northern territory. Aust Parasites Vectors 2011, 4(1):198.

doi:10.1186/s13071-014-0513-7

Cite this article as: Wei et al:: A city park as a potential epidemic site of scrub typhus: a case-control study of an outbreak in Guangzhou, China. Parasites \& Vectors 2014 7:513.

\section{Submit your next manuscript to BioMed Central and take full advantage of:}

- Convenient online submission

- Thorough peer review

- No space constraints or color figure charges

- Immediate publication on acceptance

- Inclusion in PubMed, CAS, Scopus and Google Scholar

- Research which is freely available for redistribution 